Military Technical College, Kobry El-Kobbah, Cairo, Egypt

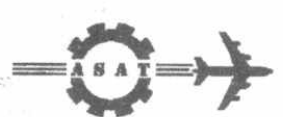

$9^{\text {th }}$ International Conference

On Aerospace Sciences \&

Aviation Technology

\title{
EXPERIMENTAL AND FINITE ELEMENT ANALYSIS FOR COMPOSITE AIRCRAFT STRUCTURES.
}

\author{
ASHAWESH* M.G.
}

\begin{abstract}
World over composite materials are being increasly employed in a variety of aerospace applications because of its inherent advantages. The present work examines both experimental and analytical (FE) analysis conducted on a composite wing box of an aerobatic aircraft. Results are referred in the form of gain, phase, and coherence for a selected number of locations on composite the wing box are further processes to yeild to the the main eigenvalues and eigenvectors. The natural frequencies and mode shapes of the wing box considered as the main dynamic characteristics are only given. The experimental investigations of the wing box are reviewed briefly in this paper.
\end{abstract}

Representitive finite element models simulating the actual composite wing box are subsequently developed. The paper further looks in to the pertinent details relating to these developments and gives an approach used in establishing the final finite element model, employed for comparative study. The paper also discusses the finite element models generated, using MSC/PATRAN, and analyzed using the standard FE, MSC/NASTRAN software.

Results from both of the above analysis are compared and discussed. It is shown how often, particularly in the case of composite structures, differences may arise in these comparisons. These differences are discussed and measures sought to identify and or eradicate the differences. The attemp at this stage, is to evaluate the magnitude and possible reasons for the differences and to seek measures to minimize them. Complexities of composite structures are well known as are the difficulties of attaining appropriate composite structure section properties. It is felt that the analytical (FE) model generated is true representitive of the real wing box.

\section{KEY WORDS}

Modal analysis, Structural dynamics, Aircraft composite structures, Composite materials, Finite element analysis

- Lecturer, Department of Aerospace Engineering, Engineering College, Tajoura, Libya. 


\section{INTRODUCTION}

In recent years composite materials are being increasly employed in a variety of aerospace applications because of its obvious merits. The present investigation examines the dynamic and subsequently the aeroelastic behaviour of a composite wing box. The material of the wing box structure is made of a Carbon Fibre Reinforced Plastic (CFRP) whose details are given in [1]. This wing box is ment as a possible replacement for the metal wing currently on the Cranfield A1 aerobatic aircraft. Fig. 1 shows the some of the important wing parameters of the whole of the aircraft. The physical wing box measures over $4 \mathrm{~m}$ in the spanwise direction and around $0.8 \mathrm{~m}$ at the root section and $0.37 \mathrm{~m}$ at the the tip section as shown in Fig. 2 .

Due its beneficial properties a composite wing box made from CFRP is constructed for post buckling behaviour of the wing box [1]. This wing box subsequently adopted for vibration analysis and mounted with securing the wing box root by attaching to a rigid concrete structure as a rigid foundation simulating a fixed free condition. The wing box is vibrated using both random and sinusoidal methods. The response is measured over the entire wing box. The natural frequencies and mode shapes of the composite wing box are presented here only as illustrated in Figs. (4-9).

Also as a part of investigations, Finite Element (FE) models of the composite wing box are generated using a pre-peocessing commertial package MSC/PATRAN, and then analyzed using the finite element software MSC/NASTRAN [5]. Normal mode analysis solution is selected for the analysis to abtain the eigenvalues and the associated eigevectors for the wing box, which are illustrated in Figs. (10-15). These investigations are ment to illuminate the ease and difficulty of simulating composite structures and to verify the use of analytical techniques for determining the dynamic charateristics. of a physical aircraft structures.

\section{EXPERIMENTAL SET UP OF THE COMPOSITE WING BOX}

A detailed description of the wing box is not dealtwith and is as per the reeference [13]. However, it deals with a comperhinsive discussion. Suffice it to say that the A1 aerobatic metal wing is modeled as a composite wing box, constructed from (CFRP). Fig. 2 shows the primary dimensions of the tested wing box, having a semi-span of $4050 \mathrm{~mm}$ from aircraft centre line, $812.8 \mathrm{~mm}$ root chord and $369 \mathrm{~mm}$ tip chord. The composite wing box is attached to a lagre rigid concrete structure as an ideal foundation, to simulate the cantilevered boundary condition.

As in any vibration test, setting up of the wing box for a vibration test is very issential and importatnt. A power amplifier, signal generator and filter unit are connected to the shaker, which provide the input required vibrate the wing structure. An electromagnetic exciter is used to shake the composite wing box. The exciter is located at the tip of the wing box at the intersection of the tip rib and the middle stringer of the bottom section through a sting as suggested by [4]. A force transducer is also connected to the sting directly onto the lower surface of the wing box. The reference accelerometer is positioned directly opposite to the load cell on the upper surface of the wing box. 
Fig. 2 shows a total of eleven accelerometers are calibrated and used in five complementary tests to measure the response of the entire wing box. Thus a total of 46 possible locations at which the output from the vibratory experiment could be retrieved. The wing box is vibrated in the frequency range of 0 to $300 \mathrm{~Hz}$. The more comperhensive details of the experimental investigations are as per [3].

\section{FINITE ELEMENT MODEL OF THE COMPOSITE WING BOX}

Several ananlytical models of the composite wing box are constructed using the dimensions derived from the actual wing and the composite wing box. The wing root and tip aerofoil sections are modeled as NACA 23015 and NACA 23012 rspectively using [6]. The model also consists of a 3 degree dihedral angle at the rear spar and 2.76 degree at the front spar.

A methodical approach is applied, by first generating a model that simulated the physical, material and the geometric properties of the wing box. It is represented as a beam with a lumped masses modeled along the flexural axis of the model using MSC/PATRAN and analyzed by MSC/NASTRAN programs. This is then replaced by a more detailed and consequently more representative wing model having metallic properties. The eigenvalues and associated mode shapes of both wing models (isotropic material) are compared and found in a good agreement [3].

Several alternative analytical models are subsequently developed starting with the above simple beam model and finishing up with a detailed fine mesh composite wing box model as shown in Fig. 3. The main purpose of this approach is to ensure a consistency in the model development and means of verification at early stages in the analysis and development process. Three types of elements are used in modeling of the composite wing box. These are quadrilateral plate (CQUAD4) element, Triangular plate (CTRIA3) element, and solid (CHEXA8) element. Four different material properties are used for the CFRP wing box necessitated by the construction of the structure. Theses are unidirectional material, unidirectional woven material and polymethylacrylate foam (Rohacell 51 and 71). Comperhnsive details about the wing models and their material properties can be found in [3]. The final analytical model (fine mesh) is comprised of spars filled with a foam, ribs, hat section stringer filled with a foam, and upper and lower skin with a total of 19000 elements as shown in Fig. 3, where as 5690 elements in the case of final model (corse mesh). Important issues like the trade off between model complexity, simplicity and the cost of analysis and accuracy is also considered.

\section{RESULTS}

Considerable amount of data in the form of gain, phase and coherence plots acquired for a total of $\mathbf{4 6}$ separate locations for the five sets of experimental tests conducted is analyzed. After close inspections, six main resonance frequencies are then identified by its peaks and presented in table 1 for the composite wing box. The eigenvalues for the six resonance conditions, from the finite element analysis, are also given in table 1. 
Normal mode analysis using the Lanczos method, via MSC/NASTRAN, is employed for both composite wing models (fine and coarse meshs).

Table 1 Natural frequencies for the composite wing box.

\begin{tabular}{|c|c|c|}
\hline $\begin{array}{c}\text { Mode } \\
\text { Number }\end{array}$ & $\begin{array}{c}\text { Experimental analysis } \\
\text { Frequency }(\mathrm{Hz})\end{array}$ & $\begin{array}{c}\text { Analaytical analysis }(\mathrm{FE}), \text { Fine model } \\
\text { Frequency }(\mathrm{Hz})\end{array}$ \\
\hline 1 & 19.740 & 25.60 \\
\hline 2 & 73.850 & 86.0 \\
\hline 3 & 142.415 & 170.43 \\
\hline 4 & 158.081 & 177.42 \\
\hline 5 & 232.43 & 253.54 \\
\hline 6 & 254.72 & 274.94 \\
\hline
\end{tabular}

The first six eigenvalues and associated mode shapes of fine CFRP wing model are shown in Figs. 10-15. It can be seen on comparing Figs 4-6 with Figs 10-12 and Figs. 7-9 with Figs. 13-15 that there is close proximity of results between the mode shapes obtained from experimental and analytical investigations. It will suffice to note that apart from the fourth mode, see Fig. 7 and 13 all the modes shapes are very similar to each other. On close inspection it would appear that Fig. 13 represents a coupled second bending-torsion mode where as Fig. 7 represents a coupled third bendingtorsion mode.

It is interesting to note that a similar trends are exhibited by the analytical model as compared with the experimental results. As apparent from the experimental results there is a similar large frequency separation between the first and second modes. Likewise there is also a large separation between the second and third frequencies. While as observed earlier, the third $(170.43 \mathrm{~Hz})$ and fourth $(177.42 \mathrm{~Hz})$ frequencies are relatively close to each other.

The third mode, at $170.43 \mathrm{~Hz}$, which represents the $3^{\text {rd }}$ bending mode as shown in Fig. 12. The fourth mode at $177.42 \mathrm{~Hz}$, illustrates a coupled bending-torsion mode, see Fig.13. This is further confirmed by noting that the frequencies of the third and fourth modes are quite close to each other. The fifth mode, at $253.54 \mathrm{~Hz}$, is the fourth bending mode as shown in Fig.14. Finally the sixth mode, at $274.94 \mathrm{~Hz}$ is represents the tip bending and torsion mode as shown in Fig.15.

\section{DISCUSSION AND COMPAISON OF RESULTS}

It is apparent from the comparison of the natural frequencies from both analysis shown in table 1 that the fundamental frequency variation is in the region of $23 \%$ reducing to a more acceotable $7 \%$ for the sixth mode. This indicates a significant difference illustrating the complexity, difficulties mainly because of the assumption in 
the analytical model of a real composite structure compared to the prototype of the composite structure.

The differences in the magnitude of the eigenvalues is largly indicative of the possible variation of the stiffness of the actual wing box as compared with the analytical model (FE).

In order to further verify this, static tests are conducted on both the physical and the analytical model. Loads of increasing magnitudes are applied at the tip rib and the deflections at the tip measured by a dial gauge as presented in table 2 . From this the appropriate stiffness of the structure is estimated. Reference [1] presents presents results from experimental test in 1984-1987 to find the tip deflection of this composite wing box under total ultimate load of $28.25 \mathrm{KN}$. This load is applied as $2 / 3$ on the front spar and $1 / 3$ on the rear spar along the semi-span of the composite wing box. The tip deflection is $132 \mathrm{~mm}$ at tip rib.

The same loading condition is then applied to the analytical model (fine model) which gives deflection of $124 \mathrm{~mm}$ at the tip rib. The difference of $6.06 \%$ between [1] and the analytical model is acceptable. Referring to the results presented in table 2, it is not too surprising to note that the analytical model is $25 \%$ stiffer than the physical structure due to the age of the wing box and other reasons.

Table 2 Comparisons of static tip deflections of actual wing box and analytical model

\begin{tabular}{|c|c|c|c|}
\hline $\begin{array}{c}\text { Wing station from } \\
\text { AVC center line } \\
(\mathrm{mm})\end{array}$ & Load $(\mathrm{N})$ & $\begin{array}{c}\text { Physical Structure } \\
\text { Deflection } \\
(\mathrm{mm})\end{array}$ & $\begin{array}{c}\text { FE Fine Model } \\
\text { Deflection } \\
(\mathrm{mm})\end{array}$ \\
\hline 4281 & 152 & 2.43 & 1.93 \\
\hline$=$ & 231 & 3.70 & 2.938 \\
\hline$=$ & 276 & 4.40 & 3.503 \\
\hline$=$ & 320 & 5.10 & 4.068 \\
\hline$=$ & 365 & 5.80 & 4.633 \\
\hline$=$ & 409 & 6.50 & 5.198 \\
\hline$=$ & 454 & 7.25 & 5.763 \\
\hline$=$ & 2295 & 36.25 & 29.15 \\
\hline
\end{tabular}

From the above static investigations, it is found that the static test conducted by [1] gives a good agreement compared with analytical static analysis under $28.25 \mathrm{KN}$. However, significantly large difference is obtained from the other analytical static
analysis and static test [3] as shown in table 2 .

There could be numerous reasons leading to this large variation in the natural frequencies between the experimental and the analytical model. In breif, these variations may attributed to the factors like age of the composite wing box, the 
previous history of post buckling of this structure, the deterioration of structural integrity of this composite structure with the age, the effects of delamination of the composite plies, moisture and the environmental effect, modeling differences between the real structure and the analytical model, the use of inappropriate boundary conditions and indeed a combination of some or all of the above.

\section{CONCLUSIONS}

The present study demonstrates that vibration experiments could be seen successful, yeilding to six natural frequencies and associated mode shapes. These results are representitive of the CFRP wing box with cantilevered boundary condition and provide useful initial data. Likewise the analytical analysis is also successful in yeilding similar natural frequencies and mode shapes.

In general despite the large variation in the natural frequencies the investigations appears to be by and large successful. It has immensely assisted in understanding the fundamentals of the dynamic properties of the composite wing box. The close similarity of the eigen modes gives some confidence in the FE model which although representitive is not an exact replica of the real structure.

This paper based upon two different types of analysis (experimental and analytical) illustrates that a large variation in results can arise when dealing with complex composite structurs. However, agreat care is needed in the reliance of these analytical methods on their own, in the light of experience gained from these investigations. With aircraft due to be in operation for tens of years the origional analytical models may not be representative of the actual structure on the apron or in the air. Indeed there is a need to revisit and perhaps reevaluate the analytical models as the life of the aircraft progresses. Thus practitioners are cautioned that some significant differences may occur, particularly with complex composite structures, which may lead to a difference between experimental and analytical results.

\section{REFERENCES}

[1] Brooks, G.W. Design, Construction and Test of a post buckling Carbon Fibre Reinforced Plastic wing box. PhD Thesis, Cranfield University, UK, (1987).

[2] Potter, G.J., and Ward, E.R. Design of aerobatic aircraft MSc Thesis, Cranfield University, UK, (1968).

[3] Ashawesh, M.G., Flutter Behaviour of Composite aircraft wings . PhD Thesis, Cranfield University, UK, (1999).

[4] Danirl, J.I., Vibration with Control, Measurement, and Stability, Prentice Hall, (1989).

[5] Rodden, P.W. and Johnson, H.E., Dynamic analysis hand book for MSC/NASTRAN Verson 69, The Macneal-Schwendler, (1994).

[6] Abbot, I.H., and Von Doenhoff, A.E., Theory of wing sections, Dover Publications, New York, (1959). 


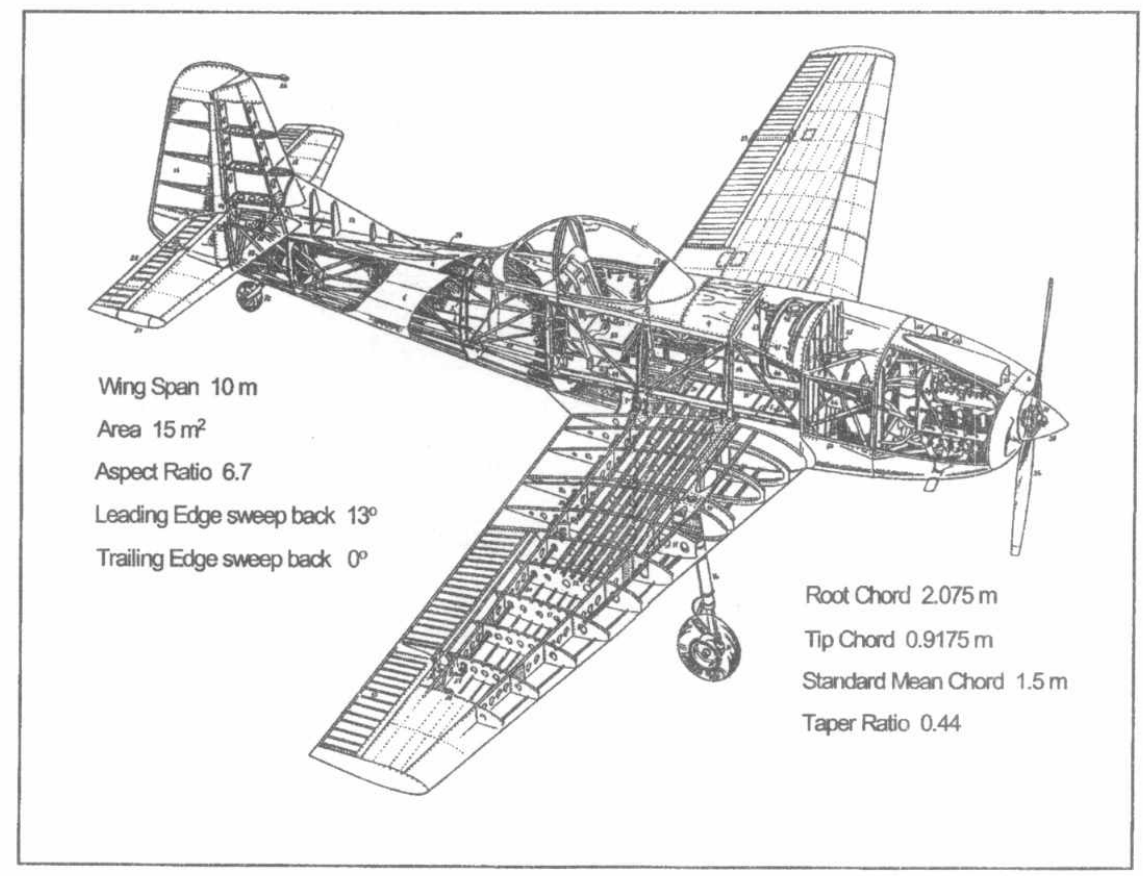

Figure 1 Cranfield A1 Aerobat with salient wing parameters. 


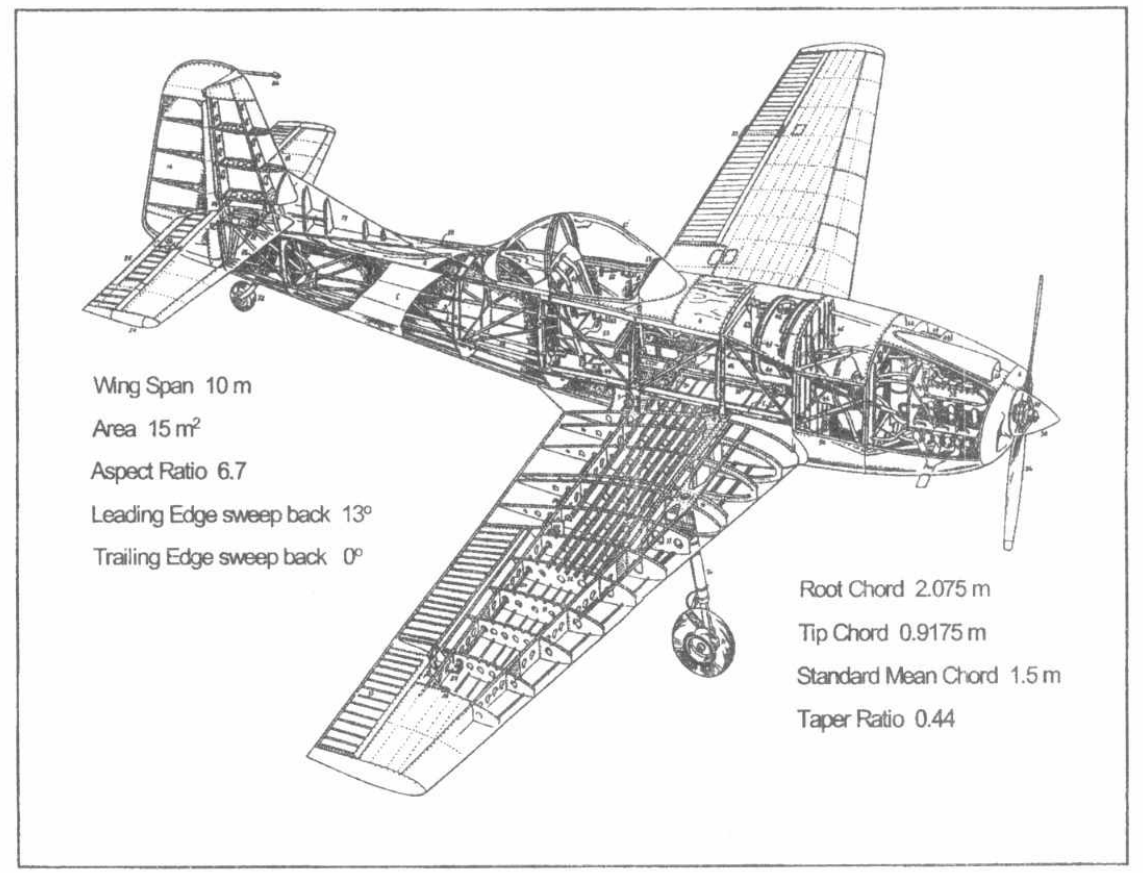

Figure 1 Cranfield A1 Aerobat with salient wing parameters. 


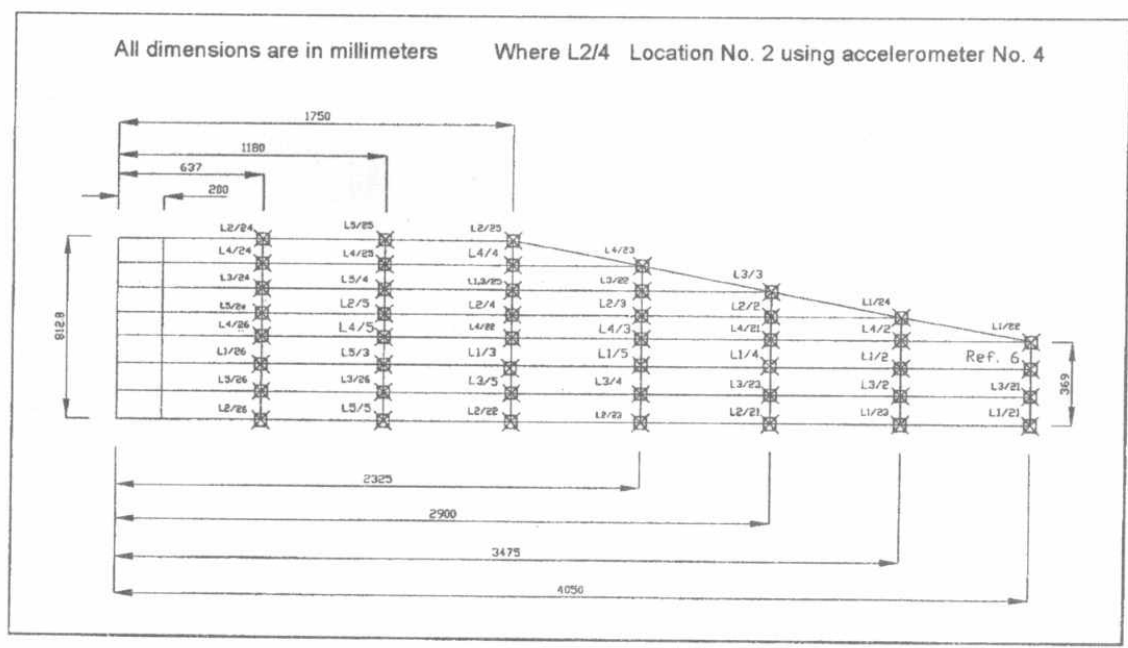

Figure 2 Plane view of the composite wing box

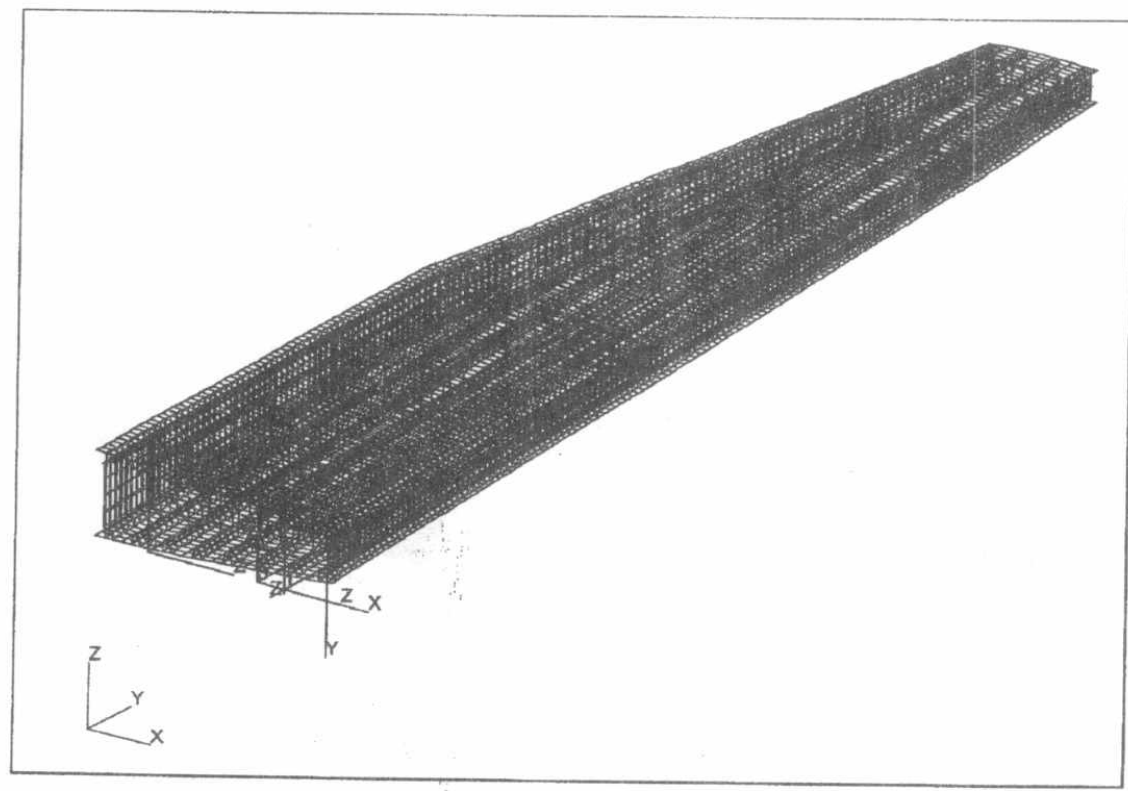

Figure 3 Finite element model (fine mesh) of the A1 composite wing box. 


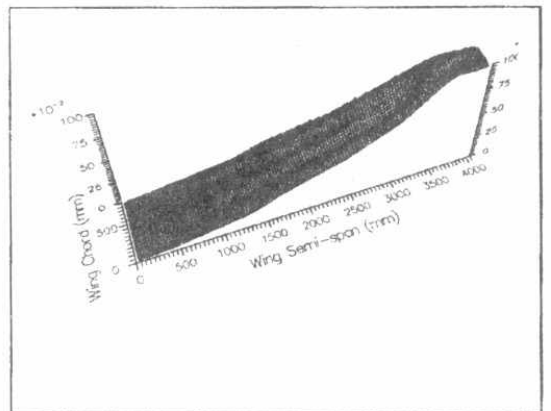

Figure $41^{\text {st }}$ bending mode $(19.74 \mathrm{~Hz})$ for the real wing box

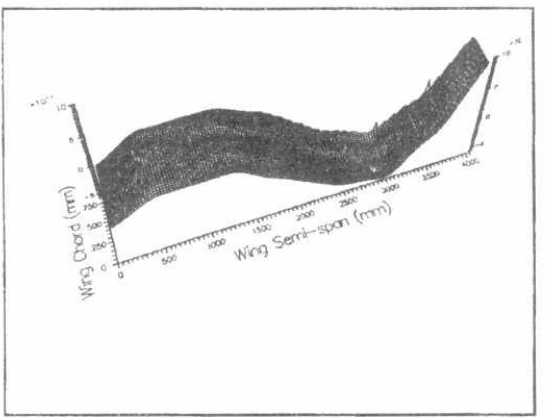

Figure $63^{\text {rd }}$ bending mode $(142.415 \mathrm{~Hz})$ for the real wing box

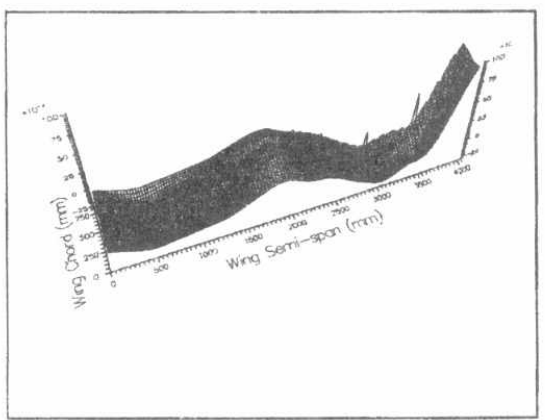

Figure $84^{\text {th }}$ bending mode $(232.43 \mathrm{~Hz})$ for the real wing box

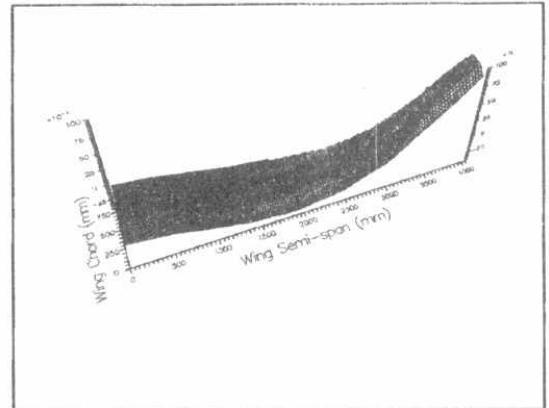

Figure $52^{\text {nd }}$ bending mode $(73.85 \mathrm{~Hz})$ for the real wing box

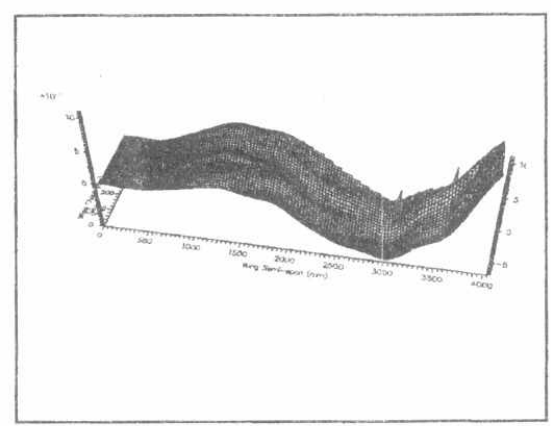

Figure 7 Coupled bending-torsion mode $(158.081 \mathrm{~Hz})$ for the real wing box

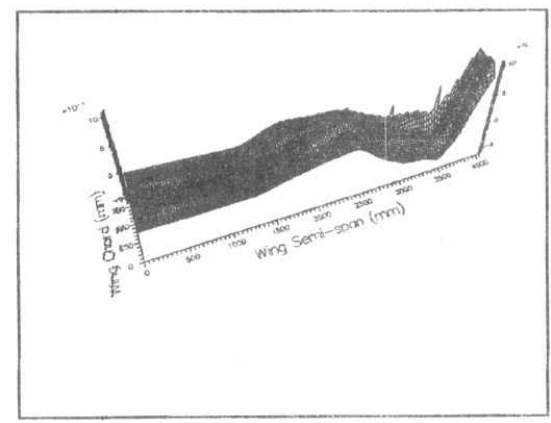

Figure 9 Tip bending-torsion mode $(254.72 \mathrm{~Hz})$ for the real wing box 


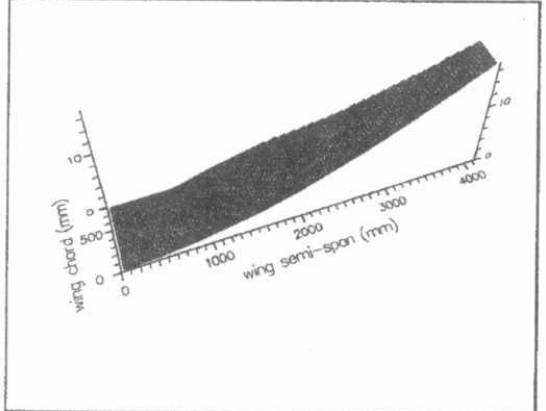

Figure $101^{\text {st }}$ Bending Mode $(25.60 \mathrm{~Hz})$ for the FE model

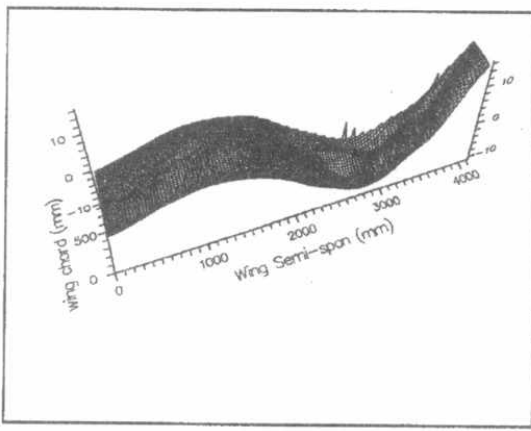

Figure $123^{\text {rd }}$ Bending Mode $(170.43 \mathrm{~Hz})$ for the FE model

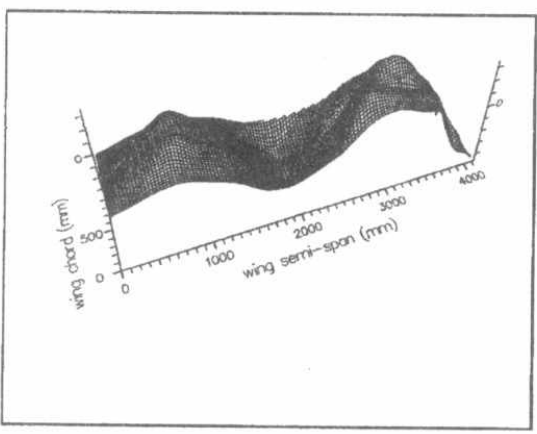

Figure $144^{\text {th }}$ Bending Mode $(253.54 \mathrm{~Hz})$ for the FE model

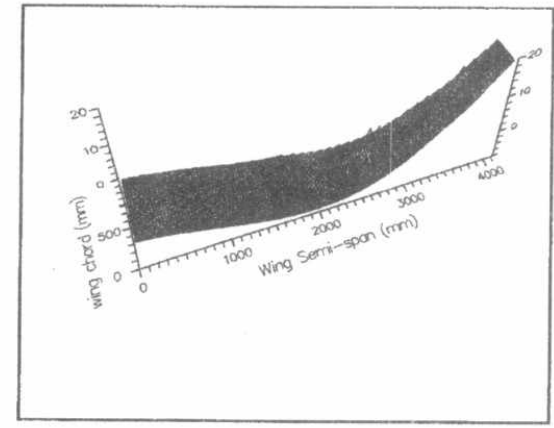

Figure $112^{\text {nd }}$ Bending Mode $(86.0 \mathrm{~Hz})$ for the FE model

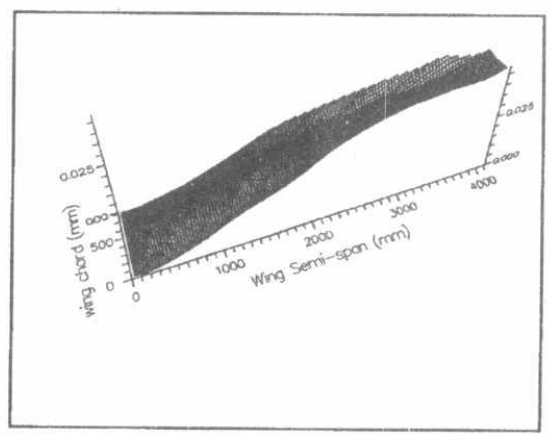

Figure 13 Coupled bending-torsion Mode $(177.42 \mathrm{~Hz}$ ) for the FE model

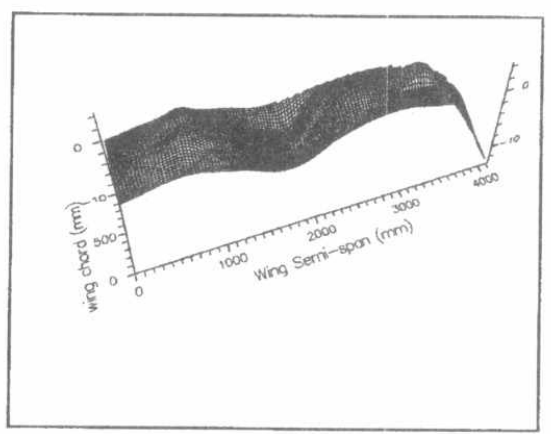

Figure 15 Tip bending-torsion Mode $(274.94 \mathrm{~Hz})$ for the FE model 